\title{
Comparative Effect of Atorvastatin and Rosuvastatin on 25-hydroxy- Vitamin D Levels in Non-diabetic Patients with Dyslipidaemia: A Prospective Randomized Open-label Pilot Study
}

\author{
Panagiotis Anagnostis ${ }^{*}{ }^{1,2}$, Fotini Adamidou ${ }^{1}$, Aristidis Slavakis ${ }^{3}$, Stergios A. Polyzos ${ }^{1}$, Despina \\ Selalmatzidou ${ }^{1}$, Athanasios Panagiotou ${ }^{1}$, Vasilios G. Athyros ${ }^{2}$, Asterios Karagiannis ${ }^{2}$ and Marina Kita ${ }^{1}$ \\ ${ }^{1}$ Department of Endocrinology, Hippokration Hospital, Thessaloniki, Greece \\ ${ }^{2}$ Second Propedeutic Department of Internal Medicine, Medical School, Aristotle University of Thessaloniki, \\ Hippokration Hospital, Thessaloniki, Greece \\ ${ }^{3}$ Department of Biochemistry, Hormone Assay Laboratory, Hippokration Hospital, Thessaloniki, Greece
}

\begin{abstract}
Aims: Low 25-hydroxy-vitamin D [25(OH)D] levels have been associated with increased risk for cardiovascular disease. Conflicting data exist regarding the effect of statins on $25(\mathrm{OH}) \mathrm{D}$ levels. The aim of this study was to compare the effect of atorvastatin and rosuvastatin on $25(\mathrm{OH}) \mathrm{D}$ levels in non-diabetic patients with dyslipidaemia.

Methods: This was a prospective randomized open-label study. Patients were assigned to atorvastatin $20 \mathrm{mg} / \mathrm{day}$ ( $\mathrm{n}=28$, age: $56.1 \pm 2.2$ years, 22 females) or rosuvastatin $10 \mathrm{mg}$ /day ( $\mathrm{n}=24$, age: $57.4 \pm 1.9$ years, 20 females). Total cholesterol (TC), low- (LDL-C) and high-density lipoprotein cholesterol (HDL-C), triglycerides (TG), fasting plasma glucose, insulin, glycosylated haemoglobin $\mathrm{A}_{1 \mathrm{c}}\left(\mathrm{HbA}_{1 \mathrm{c}}\right)$ and high sensitivity C-reactive protein (hsCRP) levels were measured, and homeostatic model of assessment insulin resistance (HOMA-IR) was calculated at baseline and 12 weeks post-treatment.

Results: There were no within or between group significant differences in $25(\mathrm{OH}) \mathrm{D}$ levels (atorvastatin: $21.7 \pm 1.9 \mathrm{ng} / \mathrm{ml}$ at baseline and $23.5 \pm 2.3 \mathrm{ng} / \mathrm{ml}$ at week 12 ; rosuvastatin: $25.3 \pm 1.8$ and $27.0 \pm 2.4 \mathrm{ng} / \mathrm{ml}$, respectively; $\mathrm{p}=0.172$ and $\mathrm{p}=0.306$ for between groups, respectively). Both statins significantly reduced TC, TG and LDL-C levels, with a greater LDL-C reduction being observed by rosuvastatin.
\end{abstract}

Conclusion: Atorvastatin and rosuvastatin did not significantly affect $25(\mathrm{OH}) \mathrm{D}$ levels in this study.

Keywords: $25(\mathrm{OH}) \mathrm{D}$, atorvastatin, glucose homeostasis, rosuvastatin, systemic inflammation, vitamin D.

\section{INTRODUCTION}

The 3-hydroxy-3-methylglutaryl coenzyme A (HMG-CoA) reductase inhibitors (statins) are the first-line agents for the treatment of hypercholesterolaemia and have been associated with a substantial reduction in cardiovascular disease (CVD) events [1,2]. Apart from their lipid-lowering action, these agents exert some cholesterolindependent effects, also known as "pleiotropic effects", such as improve-ment in endothelial function, stabilization of atherosclerotic plaque and inhibition of vascular inflammation and oxidative stress [3]. It has been proposed that some of these actions may be partly mediated through their effect on vitamin D metabolism $[4,5]$. In this regard, some studies have shown a beneficial effect of statins on 25hydroxy-vitamin D [25(OH)D] levels, the main indicator of

*Address correspondence to this author at the Department of Endocrinology, Hippokration Hospital of Thessaloniki, Sarantaporou 10, Thessaloniki, 54 640, Greece; Tel: +30 2310257150;

Fax: +30 2310 281179; E-mail: anagnwstis.pan@ yahoo.gr vitamin D status [4-7]. However, other studies have not shown any effect [8-10], although various doses of statins and different populations were studied. The effect of statins on vitamin D status may be relevant because there is some evidence that suggests that low $25(\mathrm{OH}) \mathrm{D}$ levels are associated with increased CVD morbidity and mortality [11, 12].

The aim of the present study was to evaluate the comparative effect of atorvastatin and rosuvastatin at equivalent doses on 25(OH)D levels in non-diabetic patients with dyslipidaemia, who have not met the goals for lowdensity lipoprotein cholesterol (LDL-C).

\section{MATERIALS AND METHODS}

Study Design and Subjects

This was a 12-week prospective randomized open-label pilot study conducted at the Department of Endocrinology in Hippokration General Hospital (Thessaloniki, Greece), a tertiary referral center for endocrinology and diabetes. The study was conducted from September 2011 to April 2012. It 
was approved by the local ethics committee and all the participants provided their informed consent.

We included patients $\geq 18$ years of age with dyslipidaemia not meeting the goal for LDL-C, according to the European Society of Cardiology (ESC) and the European Atherosclerosis Society guidelines for the management of dyslipidaemias [13]. Exclusion criteria were: 1) diabetes mellitus (DM) or treatment with any anti-diabetic medication; 2) malignancy; 3) thyroid or parathyroid dysfunction; 4) hypercalcemia or hypocalcemia; 5) pregnancy or breast feeding; 6) a history of adverse reaction to statins; 7) transaminase level $>2 x$ and creatine kinase $(\mathrm{CK})>3 \mathrm{x}$ the upper limit of normal range; 8) use of the following medications within a 3-month period before screening: cholecalciferol or other vitamin D supplementation, calcium supplementation, lipid-lowering or anti-obesity agents and corticosteroids.

At screening, physical examination and laboratory assessment were performed, including lipid profile [total cholesterol (TC), high-density lipoprotein cholesterol (HDLC) and triglycerides (TG)], fasting plasma glucose, haemoglobin $\mathrm{A}_{1 \mathrm{c}}\left(\mathrm{HbA}_{1 \mathrm{c}}\right)$, urea, creatinine, uric acid, $\mathrm{CK}$, aspartate aminotransferase (AST) and alanine aminotransferase (ALT) levels. Anthropometric parameters, such as body mass index (BMI), systolic and diastolic blood pressure (BP) and waist circumference (WC) were recorded at the screening visit. LDL-C was calculated according to the Friedewald equation.

Patients were randomly assigned to receive either atorvastatin $20 \mathrm{mg}$ (group A) or rosuvastatin $10 \mathrm{mg}$ (group B) once daily for 12 weeks. Randomization was performed by Microsoft Excel software before baseline assessment. The statin was discontinued and the subjects were withdrawn from the study in case of drug intolerance, pregnancy, AST and/or ALT elevation $>3 \mathrm{x}$ or $\mathrm{CK}>10 \mathrm{x}$ the upper limit of normal range. We used some serum samples from patients from our previously published study [14], kept at $-27^{0} \mathrm{C}$, if they fulfilled the present study's criteria. We further extended the study by enrolling 19 patients (during the same seasonal period).

\section{Assessments}

All blood samples were obtained between 8:00 and 9:00 am after an overnight fast. Basal laboratory parameters, as mentioned at the screening visit, $25(\mathrm{OH}) \mathrm{D}$, serum insulin and hsCRP levels were measured at baseline and 12 weeks. Insulin resistance (IR) was calculated using the homeostatic model of assessment IR (HOMA-IR), calculated by the following formula: [fasting serum insulin $(\mu \mathrm{IU} / \mathrm{L}) \mathrm{x}$ fasting plasma glucose (mmol/L)]/22.5 [15].

Biochemical parameters were measured with standard methods using an automated analyzer (Olympus AU2700; Olympus, Hamburg, Germany). Insulin and 25(OH)D were measured with immuno-chemiluminescence (ICMA) on an Immulite 2500 automated immunoassay system (Siemens Healthcare Diagnostics, Deerfield, IL); intra-assay and total coefficient of variation (CV) was 3.3-5.5\%, and 4.1-7.3\% for insulin, and $2.9-5.5 \%$ and $6.3-12.9 \%$ for $25(\mathrm{OH}) \mathrm{D}$, respectively. hsCRP was measured with latex-enhanced immunonephelometric assay on a BNII analyzer (Siemens Healthcare Diagnostics, Deerfield, IL, USA; total CV 4.0-5.0\%).

\section{Statistical Analysis}

Data for continuous variables are presented as mean \pm standard error of the mean (SEM). Data for categorical variables are presented as numbers and/or percentages. The normality of distribution of continuous variables was assessed by the Kolmogorov-Smirnov test. The paired t- or Wilcoxon Signed Ranks test was used to assess within variables differences. The independent t- or Mann-Whitney test was used to evaluate between group differences. Pearson's or Spearman's coefficients were used to assess correlations. A two-sided $\mathrm{p}<0.05$ was considered significant. A power calculation could not be performed because of the heterogeneity of previous studies with regard to the population included and baseline $25(\mathrm{OH}) \mathrm{D}$ levels. Statistical analysis was performed using SPSS for Windows version 17 (SPSS Inc., Illinois, USA).

\section{RESULTS}

\section{Patient Characteristics}

In total, 63 patients were randomly assigned to atorvastatin $20 \mathrm{mg} /$ day (group A) or rosuvastatin $10 \mathrm{mg} /$ day (group B), 4 of which were lost to follow-up and 7 withdrew the drug due to adverse events. Therefore, 52 patients completed the study, 28 from group A (aged 56.1 2.2 years, 22 females) and 24 from group B (aged 57.4 \pm 1.9 years, 20 females).

The two groups were comparable at baseline in terms of anthropometric parameters including age, gender, weight, systolic and diastolic BP, BMI and WC. The clinical characteristics of the patients at baseline and at 12 weeks are presented in Table 1. No significant differences were noted regarding these parameters after treatment.

\section{Effect of Statins on 25(OH)D Levels}

There were no statistically significant differences between the two groups at baseline and week 12 in serum $25(\mathrm{OH}) \mathrm{D}$ levels. No significant difference was also observed in $25(\mathrm{OH}) \mathrm{D}$ levels after treatment within either group (Table 2).

\section{Effects of Statins on Lipid Levels}

There was no significant difference between the two groups in terms of baseline lipid levels (Table 2). In both groups, TC, TG and LDL-C were significantly decreased after 12 weeks of treatment ( $p<0.001$, for either group), whereas there was a significant reduction in HDL-C levels only in group A $(p=0.007)$. The reduction in LDL-C was greater with rosuvastatin $(49.4$ vs. $41.7 \%, \mathrm{p}=0.015)$ while the reductions in TC and TG levels were similar between the 2 groups (37 vs. $32.9 \%$, respectively; $\mathrm{p}=0.05$ and 27.4 vs. $22.5 \%$, respectively; $\mathrm{p}=0.168$ ) (Table 2 ). 
Table 1. Baseline and 12-week anthropometric and clinical comparative data of both groups.

\begin{tabular}{|c|c|c|c|c|}
\hline Variable & Time & Group A $(n=28)$ & Group B $(n=24)$ & p-value (between groups) \\
\hline Female/Male & - & $22 / 6$ & $20 / 4$ & 0.736 \\
\hline \multirow[t]{2}{*}{ Body Mass Index $\left(\mathrm{kg} / \mathrm{m}^{2}\right)$} & Baseline & $30.9 \pm 0.8$ & $29.7 \pm 0.7$ & 0.322 \\
\hline & 12 weeks & $30.8 \pm 0.9$ & $29.9 \pm 0.9$ & \\
\hline \multirow[t]{3}{*}{ Waist circumference (cm) } & Baseline & $101.2 \pm 2.6$ & $98.5 \pm 2.2$ & 0.448 \\
\hline & 12 weeks & $100.9 \pm 2.5$ & $96.7 \pm 2.4$ & 0.233 \\
\hline & p-value (within group) & 0.788 & 0.096 & \\
\hline Systolic blood pressure (mmHg) & Baseline & $145 \pm 4$ & $141 \pm 5$ & 0.598 \\
\hline \multirow[t]{3}{*}{ Diastolic blood pressure (mmHg) } & Baseline & $86 \pm 4$ & $82 \pm 2$ & 0.471 \\
\hline & 12 weeks & $78 \pm 2$ & $77 \pm 3$ & 0.835 \\
\hline & p-value (within group) & 0.093 & 0.026 & \\
\hline
\end{tabular}

Table 2. Baseline and 12-week serum comparative data of both groups.

\begin{tabular}{|c|c|c|c|c|}
\hline Variable & Time & Group A $(n=28)$ & Group B $(n=24)$ & p-value (between groups) \\
\hline \multirow[t]{2}{*}{ Total cholesterol (mg/dl) } & Baseline & $284 \pm 8$ & $275 \pm 7$ & 0.388 \\
\hline & p-value (within group) & $<0.001$ & $<0.001$ & \\
\hline \multirow[t]{2}{*}{ Triglycerides (mg/dl) } & Baseline & $166 \pm 14$ & $150 \pm 14$ & 0.434 \\
\hline & p-value (within group) & $<0.001$ & $<0.001$ & \\
\hline \multirow[t]{2}{*}{ HDL-C (mg/dl) } & Baseline & $60 \pm 2$ & $60 \pm 3$ & 0.965 \\
\hline & Month 3 & $55 \pm 2$ & $59 \pm 3$ & 0.264 \\
\hline LDL-C (mg/dl) & p-value (within group) & $<0.001$ & $<0.001$ & \\
\hline \multirow[t]{3}{*}{ 25(OH)D (ng/ml) } & Baseline & $21.7 \pm 1.9$ & $25.3 \pm 1.8$ & 0.172 \\
\hline & Month 3 & $23.5 \pm 2.3$ & $27.0 \pm 2.4$ & 0.306 \\
\hline & p-value (within group) & 0.205 & 0.306 & \\
\hline \multirow[t]{3}{*}{ Serum calcium (mg/dl) } & Baseline & $9.4 \pm 0.1$ & $9.5 \pm 0.1$ & 0.442 \\
\hline & Month 3 & $9.2 \pm 0.1$ & $9.5 \pm 0.1$ & 0.133 \\
\hline & p-value (within group) & 0.069 & 0.443 & \\
\hline
\end{tabular}


Table 2. Contd....

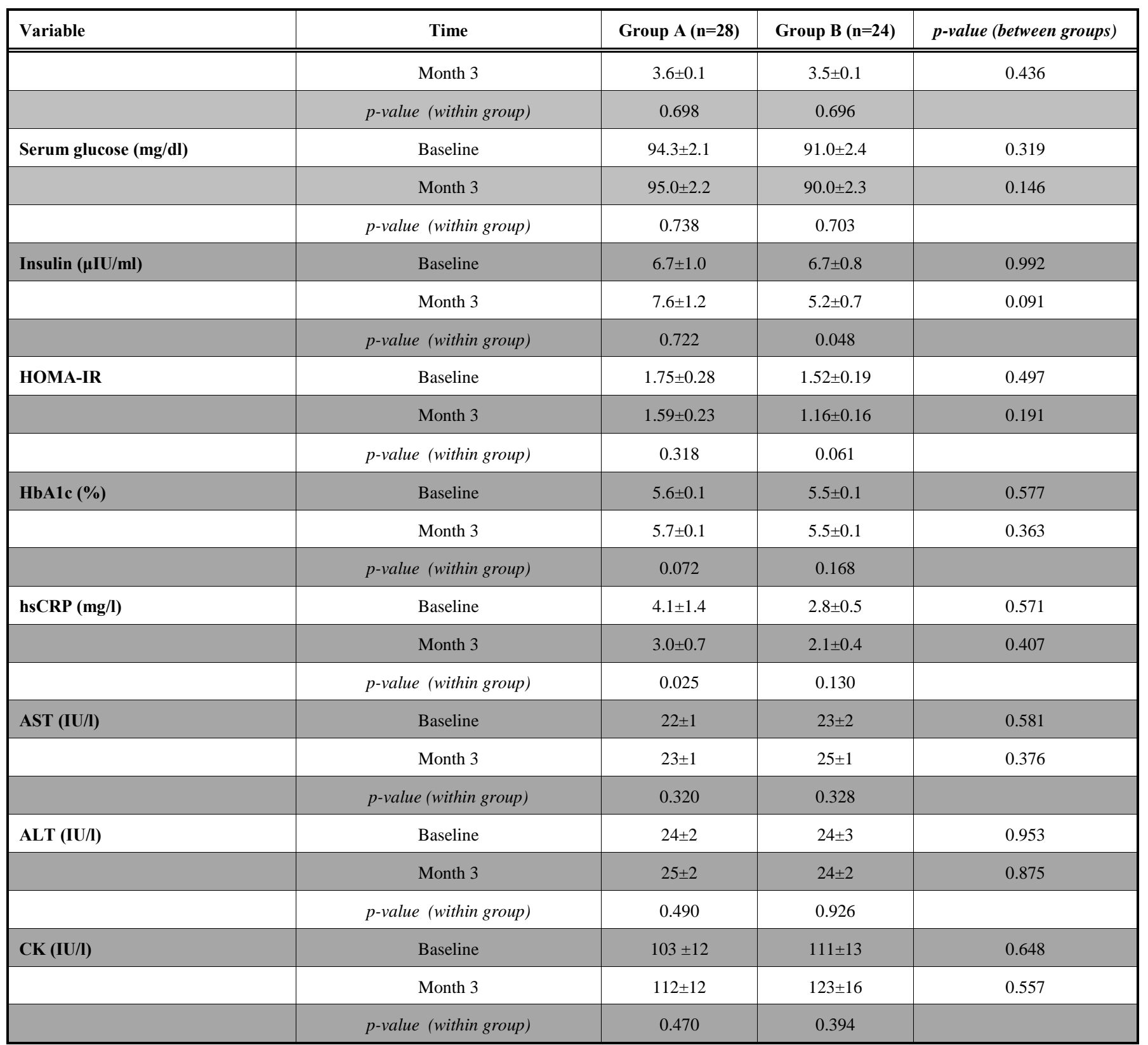

Abbreviations: LDL-C: low density lipoprotein cholesterol, HDL-C: high-density lipoprotein cholesterol, HOMA-IR: homeostasis model assessment-insulin resistance, HbA1c: haemoglobulin A1c, hsCRP: high sensitivity C-reactive protein, AST: aspartate aminotransferase, ALT: alanine aminotransferase, CK: creatine kinase.

\section{Effect of Statins on hsCRP Levels and Glucose Metabolism}

There were no significant differences between the two groups regarding baseline hsCRP, fasting plasma glucose, $\mathrm{HbA}_{1 \mathrm{c}}$, insulin and HOMA-IR levels. Regarding systemic inflammation, only atorvastatin significantly reduced hsCRP levels $(-13.5 \%, \mathrm{p}=0.025)$. In terms of glucose homeostasis, only rosuvastatin caused a significant reduction in insulin compared with baseline levels $(-8.5 \%, \mathrm{p}=0.048)$, with a tendency for reduction in HOMA-IR $(\mathrm{p}=0.061)$. The effect of both statins on fasting plasma glucose and $\mathrm{HbA}_{1 \mathrm{c}}$ levels was not significant.

\section{CORRELATIONS}

Baseline 25(OH)D levels were positively associated with insulin $\left(r_{s}=0.309, p=0.033\right)$ levels and HOMA-IR $\left(r_{s}=0.335\right.$, $\mathrm{p}=0.019)$, while no associations with hsCRP, TC, TG, LDLC, HDL-C, glucose, $\mathrm{HbA}_{1 \mathrm{c}}$ levels or anthropometric parameters was found. Baseline hsCRP was positively associated with BMI $\left(r_{s}=0.436, p=0.001\right), W C\left(r_{s}=0.426\right.$, $\mathrm{p}=0.002)$, diastolic BP $\left(\mathrm{r}_{\mathrm{s}}=0.289, \mathrm{p}=0.04\right)$ and $\mathrm{HbA}_{1 \mathrm{c}}$ $\left(\mathrm{r}_{\mathrm{s}}=0.358, \mathrm{p}=0.011\right)$. 


\section{Adverse Events}

One patient from group A and four from group B reported myalgia, without $\mathrm{CK}$ elevation, which resolved after drug discontinuation. One patient reported epigastric pain and another one dizziness in group $\mathrm{A}$, which also resolved after drug withdrawal. No significant difference within or between group was found in serum transaminases, CK, urea, creatinine or uric acid levels (Table 2 ).

\section{DISCUSSION}

The main finding of this study was that both these potent and widely-prescribed statins did not exert any significant effect on serum $25(\mathrm{OH}) \mathrm{D}$ levels. It should be emphasized that the doses of statins used in our study were broadly equivalent, based on the results of the Statin Therapies for Elevated Lipid Levels compared Across doses to Rosuvastatin (STELLAR) trial, in which $10 \mathrm{mg}$ rosuvastatin treatment was equivalent to $20 \mathrm{mg}$ atorvastatin in reducing TC, LDL-C, non-HDL-C and TG [16].

Few studies have been published regarding the effect of statins on vitamin D levels. A beneficial effect of rosuvastatin $[4,5]$ or atorvastatin $[6,7]$ has been reported by some authors, while no effect of simvastatin [8], pravastatin [9, 10] or fluvastatin [17] was reported by others. Existing data permit no general conclusions (i.e. whether there is a statin-class effect and to what extent), since different populations have been studied, with various statin doses, different baseline $25(\mathrm{OH}) \mathrm{D}$ levels and follow-up intervals. These reasons may partly account for the differences observed compared with our study. A distinct populationrelated difference in our study compared with the previous ones performed with atorvastatin or rosuvastatin is that the previous studies had enrolled patients with impaired renal or endothelial function [4], diabetes [5], acute ischemic heart disease [6] and polycystic ovary syndrome [7], whereas apparently healthy non-diabetic individuals were enrolled in our study.

Furthermore, limited comparative studies exist dealing with this issue. In a study of hyperlipidaemic patients, $10 \mathrm{mg}$ rosuvastatin increased $25(\mathrm{OH}) \mathrm{D}$ levels significantly more compared with $80 \mathrm{mg}$ fluvastatin after 8 weeks of treatment [17]. In a second study of patients with type $2 \mathrm{DM}, 10 \mathrm{mg}$ atorvastatin increased $25(\mathrm{OH}) \mathrm{D}$ levels more significantly compared with $40 \mathrm{mg}$ simvastatin, after 3 months of treatment [18]. In a third study involving hypercholesterolaemic Greek patients, simvastatin/ezetimibe 10/10 mg was associated with a greater increase in $25(\mathrm{OH}) \mathrm{D}$ levels compared with simvastatin $40 \mathrm{mg}$ (36.7 vs. $76.1 \%)$ [19]. It should be noted that mean baseline $25(\mathrm{OH}) \mathrm{D}$ concentrations in this study $(6.7-6.8 \mathrm{ng} / \mathrm{ml})$ were in the severe deficiency range $(<10 \mathrm{ng} / \mathrm{ml})$ compared with those in the aforementioned study of simvastatin treatment [8], that showed no effect on vitamin D status [mean baseline $25(\mathrm{OH}) \mathrm{D}$ levels $28 \mathrm{ng} / \mathrm{ml}$. In a fourth study in patients with mixed dyslipidaemia, high daily dose of rosuvastatin (40 mg), was compared with rosuvastatin $10 \mathrm{mg}$ plus fenofibrate $200 \mathrm{mg}$ or rosuvastatin $10 \mathrm{mg}$ plus omega- 3 fatty acids $2 \mathrm{~g}$. The increase in $25(\mathrm{OH}) \mathrm{D}$ after 3 months of treatment was significant compared with baseline, but comparable among the 3 groups. Again, the patients were vitamin $\mathrm{D}$ deficient at baseline [mean 25(OH)D concentrations were $<15 \mathrm{ng} / \mathrm{ml}$ ] [20]. All the above considering, a possible explanation for the null effect of atorvastatin and rosuvastatin on $25(\mathrm{OH}) \mathrm{D}$ levels in our study may be that baseline $25(\mathrm{OH}) \mathrm{D}$ levels were $>20 \mathrm{ng} / \mathrm{ml}$ and, thus, any increment would be difficult to achieve by statin administration. The relationship of the magnitude of $25(\mathrm{OH}) \mathrm{D}$ increment with baseline $25(\mathrm{OH}) \mathrm{D}$ levels has also been supported by others [21].

Regarding the effect of statins on hsCRP levels, only atorvastatin reduced hsCRP levels. Few comparative studies exist, evaluating equivalent statin doses, with rosuvastatin causing similar [22] or greater reduction in hsCRP levels [23]. A recent meta-analysis of randomized trials showed no significant difference between these two statins regarding their effect on hsCRP [24]. The superiority of atorvastatin vs. rosuvastatin found in this study regarding hsCRP is reported for the first time in the literature. Regarding glucose homeostasis, as shown in our previous study [14], the effect of both statins on $\mathrm{HbA}_{1 \mathrm{c}}$ and glucose levels was null, whereas rosuvastatin significantly reduced insulin levels, with a tendency towards reduction in HOMA-IR. The effect of statins on glucose metabolism still remains a matter of debate [25] and it should be emphasized that data from large interventional studies have shown that the CVD risk reduction by statins is greater in patients with type $2 \mathrm{DM}$ than in non-diabetics, thus counteracting a potential increase in CVD risk related to new-onset diabetes mellitus [26].

The strengths of the present study are its prospective randomized design, the stringent inclusion and exclusion criteria and the fact that the two groups were well-matched at baseline. However, we acknowledge certain limitations: the study was open-label rather than blinded, its duration was relatively short and the sample size was small. The differential effect of season and sunlight exposure on $25(\mathrm{OH}) \mathrm{D}$ levels in previous studies should also been taken into account when interpreting these data.

In conclusion, atorvastatin and rosuvastatin did not exert a significant effect on serum $25(\mathrm{OH}) \mathrm{D}$ levels in this study. Larger, blinded trials are needed to elucidate the impact of statins on $25(\mathrm{OH}) \mathrm{D}$ levels.

\section{CONFLICT OF INTEREST}

The authors have no conflict of interest to declare.

\section{ACKNOWLEDGEMENTS}

Declared none.

\section{REFERENCES}

[1] Baigent C, Keech A, Kearney PM, et al; Cholesterol Treatment Trialists' (CTT) Collaborators. Efficacy and safety of cholesterollowering treatment: prospective meta-analysis of data from 90,056 participants in 14 randomised trials of statins. Lancet 2005; 366 : 1267-78.

[2] Athyros VG, Kakafika AI, Papageorgiou AA, et al. Effects of statin treatment in men and women with stable coronary heart disease: a subgroup analysis of the GREACE Study. Curr Med Res Opin 2008; 24: 1593-9. 
[3] Athyros VG, Kakafika AI, Tziomalos K, Karagiannis A, Mikhailidis DP. Pleiotropic effects of statins--clinical evidence. Curr Pharm Des 2009; 15: 479-89.

[4] Ott C, Raff U, Schneider MP, Titze SI, Schmieder RE. 25hydroxyvitamin D insufficiency is associated with impaired renal endothelial function and both are improved with rosuvastatin treatment. Clin Res Cardiol 2013; 102: 299-304.

[5] Yavuz B, Ertugrul DT, Cil H, et al. Increased levels of 25 hydroxyvitamin $\mathrm{D}$ and 1,25-dihydroxyvitamin $\mathrm{D}$ after rosuvastatin treatment: a novel pleiotropic effect of statins? Cardiovasc Drugs Ther 2009; 23: 295-9.

[6] Pérez-Castrillón JL, Vega G, Abad L, et al. Effects of Atorvastatin on vitamin D levels in patients with acute ischemic heart disease. Am J Cardiol 2007; 99: 903-5.

[7] Sathyapalan T, Shepherd J, Arnett C, Coady AM, Kilpatrick ES, Atkin SL. Atorvastatin increases 25-hydroxyvitamin D concentrations in patients with polycystic ovary syndrome. Clin Chem 2010; 56: 1696-700.

[8] Rejnmark L, Vestergaard P, Heickendorff L, Mosekilde L. Simvastatin does not affect vitamin D status, but low vitamin D levels are associated with dyslipidemia: results from a randomised, controlled trial. Int J Endocrinol 2010; 2010: 957174.

[9] Montagnani M, Loré F, Di Cairano G, et al. Effects of pravastatin treatment on vitamin D metabolites. Clin Ther 1994; 16: 824-9.

[10] Ismail F, Corder CN, Epstein S, Barbi G, Thomas S. Effects of pravastatin and cholestyramine on circulating levels of parathyroid hormone and vitamin D metabolites. Clin Ther 1990; 12: 427-30.

[11] Anagnostis P, Athyros VG, Adamidou F, Florentin M, Karagiannis A. Vitamin D and cardiovascular disease: a novel agent for reducing cardiovascular risk? Curr Vasc Pharmacol 2010; 8: 72030 .

[12] El-Menyar A, Rahil A, Dousa K, et al. Low vitamin D and cardiovascular risk factors in males and females from a sunny, rich country. Open Cardiovasc Med J 2012; 6: 76-80.

[13] European Association for Cardiovascular Prevention \& Rehabilitation, Reiner Z, Catapano AL, De Backer G, et al; ESC Committee for Practice Guidelines (CPG) 2008-2010 and 20102012 Committees. ESC/EAS Guidelines for the management of dyslipidaemias: the Task Force for the management of dyslipidaemias of the European Society of Cardiology (ESC) and the European Atherosclerosis Society (EAS). Eur Heart J 2011; 32: $1769-818$.

[14] Anagnostis P, Selalmatzidou D, Polyzos SA, et al. Comparative effects of rosuvastatin and atorvastatin on glucose metabolism and adipokine levels in non-diabetic patients with dyslipidaemia: a prospective randomized open-label study. Int J Clin Pract 2011; 65: 679-83.

[15] Mojiminiyi OA, Abdella NA. Effect of homeostasis model assessment computational method on the definition and associations of insulin resistance. Clin Chem Lab Med 2010; 48: 1629-34.

[16] Jones PH, Davidson MH, Stein EA, et al; STELLAR Study Group. Comparison of the efficacy and safety of rosuvastatin versus atorvastatin, simvastatin, and pravastatin across doses (STELLAR* trial). Am J Cardiol 2003; 92: 152-60.

[17] Ertugrul DT, Yavuz B, Cil H, et al. STATIN-D Study: Comparison of the influences of rosuvastatin and fluvastatin treatment on the levels of 25 hydroxyvitamin D. Cardiovasc Ther 2011; 29: 146-52.

[18] Sathyapalan T, Shepherd J, Atkin SL, Kilpatrick ES. The effect of atorvastatin and simvastatin on vitamin $\mathrm{D}$, oxidative stress and inflammatory marker concentrations in patients with type 2 diabetes: a crossover study. Diabetes Obes Metab 2013; 15: 767-9.

[19] Liberopoulos EN, Makariou SE, Moutzouri E, Kostapanos MS Challa A, Elisaf M. Effect of simvastatin/ezetimibe 10/10 mg versus simvastatin $40 \mathrm{mg}$ on serum vitamin D levels. J Cardiovasc Pharmacol Ther 2013; 18: 229-33.

[20] Makariou SE, Liberopoulos EN, Agouridis AP, Challa A, Elisaf M. Effect of rosuvastatin monotherapy and in combination with fenofibrate or omega-3 fatty acids on serum vitamin D levels. J Cardiovasc Pharmacol Ther 2012; 17: 382-6.

[21] Yavuz B, Ertugrul DT. Statins and vitamin D: a hot topic that will be discussed for a long time. Dermatoendocrinology 2012; 4: 8-9.

[22] Betteridge DJ, Gibson JM, Sager PT. Comparison of effectiveness of rosuvastatin versus atorvastatin on the achievement of combined C-reactive protein $(<2 \mathrm{mg} / \mathrm{L})$ and low-density lipoprotein cholesterol $(<70 \mathrm{mg} / \mathrm{dl})$ targets in patients with type 2 diabetes mellitus (from the ANDROMEDA study). Am J Cardiol 2007; 100: 1245-8.

[23] Ferdinand KC, Clark LT, Watson KE, et al; ARIES Study Group. Comparison of efficacy and safety of rosuvastatin versus atorvastatin in African-American patients in a six-week trial. Am J Cardiol 2006; 97: 229-35.

[24] Takagi H, Umemoto T. A meta-analysis of randomized head-tohead trials of atorvastatin versus rosuvastatin for reductions in C-reactive protein. Int J Cardiol 2012; 154: 78-81.

[25] Anagnostis P, Athyros VG, Karagiannis A, Mikhailidis DP. Impact of statins on glucose metabolism-a matter of debate. Am J Cardiol 2011; 107: 1866

[26] Athyros VG, Tziomalos K, Karagiannis A, Mikhailidis DP. Lipidlowering agents and new onset diabetes mellitus. Expert Opin Pharmacother 2010; 11: 1965-70.

Received: May 15, 2014 Revised: May 30, 2014 Accepted: May 30, 2014

(C) Anagnostis et al.; Licensee Bentham Open.

This is an open access article licensed under the terms of the Creative Commons Attribution Non-Commercial License (http://creativecommons.org/licenses/ by-nc/3.0/) which permits unrestricted, non-commercial use, distribution and reproduction in any medium, provided the work is properly cited. 